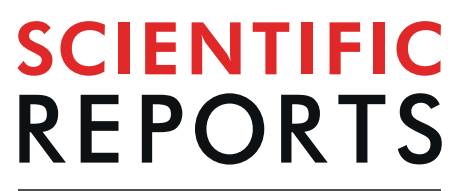

natureresearch

\title{
Synthesis of Ce-doped
}

$\mathrm{Mn}_{3} \mathrm{Gd}_{7-x} \mathrm{Ce}_{x}\left(\mathrm{SiO}_{4}\right)_{6} \mathrm{O}_{1.5}$ for the enhanced catalytic ozonation of tetracycline

\author{
Jie $\mathrm{Fu}^{1}$, Ning Liu ${ }^{1}$, Lefu Mei ${ }^{1 *}$, Libing Liao ${ }^{1 *}$, Dina Deyneko ${ }^{2}$, Jiayang Wang ${ }^{1}$, Yaning Bai ${ }^{1}$ \& \\ Guocheng Lv ${ }^{1^{*}}$
}

A novel cerium doped compounds $\mathrm{Mn}_{3} \mathrm{Gd}_{7-x} \mathrm{Ce}_{x}\left(\mathrm{SiO}_{4}\right)_{6} \mathrm{O}_{1.5}$ with an apatite structure was found and used to achieve high-efficiency degradation of tetracycline in aqueous solution. The catalysts were characterized by XRD, XPS, EDS and other techniques. The characteristic results indicated that the catalytic activity of the compound was improved due to the introduction of $\mathrm{Ce}$ in the structure, because $\mathrm{Ce}^{3+}$ which was stably present in the apatite structure can serve as an active site for the reaction, and in addition, there was a high presence between $\mathrm{Ce}^{4+}$ and $\mathrm{Ce}^{3+}$ on the surface of the catalyst. The redox potential and high oxygen storage capacity were also beneficial for the catalytic reaction. The results of free radical capture indicated that both superoxide radicals and hydroxyl radicals participated in the catalytic oxidation process and played an important role in the reaction. The decomposition of tetracycline followed the pseudo second-order reaction kinetics. In addition, the catalyst exhibited long-term stability and low metal leaching during the reaction, which indicated that the novel ceriumdoped apatite structure material could be a promising wastewater treatment material.

Antibiotics are extensively used in the treatment of human diseases and in livestock and aquaculture, due to their broad-spectrum and extremely strong antibacterial activity ${ }^{1}$. In recent years, with the extensive use of antibiotics in human and veterinary medicine, trace antibiotics have been detected the in drinking water, surface water, groundwater, soil, and aquatic organisms ${ }^{2}$. Due to their low metabolism rate, some antibiotics remain in the natural environment for a long time, which not only damage the balance of the ecological environment, but also causes detrimental to humans, due to their enrichment in food chains or pollution of drinking water ${ }^{4,5}$. Therefore, alongside the plans of reasonable use of antibiotics in medicines, it is important also to develop effective treatment technologies to remove antibiotics from polluted water or soil ${ }^{3}$.

Tetracycline (TC) exists in trace levels in natural waters and is difficult to decompose, and the toxicity of its primary decomposition products is comparable to or even higher than that of the parent compound ${ }^{4}$. Therefore, traditional techniques including adsorption separation ${ }^{5}$ and biodegradation ${ }^{6}$ have been investigated to remove antibiotics and other antimicrobials from water. However, the adsorption method does not destroy the structure of tetracycline and cannot achieve the effect of thorough removal. On the other hand, TC inhibits metabolism during microbial degradation. Thus, rapid and efficient treatment processes must be developed for TC degradation ${ }^{1}$.

Advanced oxidation processes (AOPs) is based on highly potent chemical species ${ }^{7}$. It has the characteristics of high efficiency ${ }^{8}$, bottom measurement, the absence of secondary pollution ${ }^{9}$ and short residence time for the treatment of refractory organic matter in water and sewage. Compared with the traditional method of wastewater treatment, it has obvious advantages such as strong oxidizing ability, non-selective simple reaction conditions, and no requirements for high temperature and pressure. It can be used not only for advanced treatment of sewage, but also in combination with other treatment technologies ${ }^{10}$. In recent years, heterogeneously catalyzed ozone oxidation technology has received extensive attention in the large-scale water treatment ${ }^{11}$. Meanwhile, in order

\footnotetext{
${ }^{1}$ Beijing Key Laboratory of Materials Utilization of Nonmetallic Minerals and Solid Wastes, National Laboratory of Mineral Materials, School of Materials Sciences and Technology, China University of Geosciences, Beijing, 100083, China. ${ }^{2}$ Chemistry Department, Lomonosov Moscow State University, 119991, Moscow, Russia. *email: mlf@cugb. edu.cn; clayl@cugb.edu.cn; guochenglv@cugb.edu.cn
} 
to achieve more efficient processing efficiency, catalysts for heterogeneous catalytic ozonation technology include transition metal oxide such as manganese dioxide, iron oxide, copper oxide, rare earth oxides, such as cerium oxide and their composites, have been reported as solid supports for the catalytic degradation. However, regardless if they are single metal oxide or compounds, there will be a certain amount of metal dissolution ${ }^{12,13}$, causing catalyst deactivation and secondary pollution, wasting of resources. Therefore, increasingly researches are focused on the way to low the amount of metal dissolution, in which introducing catalytically active metal ions into the crystal lattice is a good approach. In the context of lowing the active ion dissolution. doping of the crystal lattice with active metal ions, zhu et al. ${ }^{14}$ studied the A-position of the perovskite compound has 12 -fold coordinated positions, and the high coordination number of the active ions can effectively improve the stability of the active metal in the compound, otherwise, Wang et al. ${ }^{15}$ also reported relationship between leaching ratio and doping content. And further, by using the active metal doping into the crystal lattice can also better disperse the active elements into the crystal lattice to better improve the catalytic performance of the sample. S.I. Suárez-Váquez et al. also reported the phenomenon ${ }^{16}$, the addition of $\mathrm{Mn}$ resulted in the incorporation of $\mathrm{Mn}^{4+}$ in $\mathrm{Ti}^{4+}$ sites present into the structure of the perovskite. This incorporation also enhances the relation $\mathrm{O}_{\text {ads }} / \mathrm{O}_{\text {latt }}$ and the catalytic properties. Finally, the catalyst doped by Mn presented the highest catalytic activity ${ }^{17}$. In addition, CNTs attached by means of $\mathrm{CH}-\pi, \pi-\pi$ stacking and Van der Waals forces could make them disperse in liquid media and leave the polyaromatic pattern unaltered, and reduce catalyst deactivation.

The compounds with an apatite-type structure $\mathrm{A}_{10}\left[\mathrm{MO}_{4}\right]_{6} \mathrm{O}_{2}$ have great flexibility in their crystal lattice to accommodate a big number of substitutions ${ }^{18}$. The cations in a position can be substituted by foreign cations having different oxidation states or radii, thus increasing the number of the cation vacancies in the structure. Meanwhile, $\left[\mathrm{PO}_{4}\right]^{3-}$ ions can also be substituted by $[\mathrm{SiO} 4]^{4-},\left[\mathrm{GeO}_{4}\right]^{4-}$ anion groups under different conditions. Obviously, the component adjustment will bring a bit of active sites, to improve catalytic effect. So, it is a kind of potential candidate for catalyst designing technology.

Among the different reported catalysts, transition metal ions such as $\mathrm{Mn}$ (II), has demonstrated high efficiencies in catalytic ozonation for homogeneous degradation of various organic pollutants ${ }^{19}$. Manganese ion with the lowest state has a significant advantages as a redox medium for the removal of organic pollutants ${ }^{20}$. Besides, via the introduction of $\mathrm{MnO}_{x}$, large amount of surface hydroxyl groups are generated on the surface of catalyst, it play a key role in degradation adsorption and $\cdot \mathrm{OH}$ initiation, Higher multivalent $\mathrm{MnO}_{x}(\mathrm{Mn}(\mathrm{III}) / \mathrm{Mn}(\mathrm{IV})$ ) enhances electron transfer, which also benefits degradants removal ${ }^{17}$. To improve the catalytic activity, cerium (Ce) with a high oxygen storage capacity has been commonly used ${ }^{21}$. As such, a redox cycle between the +3 and +4 states can be manipulated to create efficient catalysts process $^{3}$. Interestingly, the doped Ce cations can enter the apatite-type lattice with equivalent substitution, and maintain the stability of the structure. Inclusion of foreign metals in the structure could lead to increases in defects inside the catalyst surface thereby creating more number of active sites $^{22,23}$

In this work, we prepared a kind of Ce-doped apatite-type compounds $\mathrm{Mn}_{3} \mathrm{Gd}_{7-x} \mathrm{Ce}_{x}\left(\mathrm{SiO}_{4}\right)_{6} \mathrm{O}_{1.5}$ using traditional high temperature solid phase method and applied it in the catalytic ozonation of TC. The results showed that strong interactions between Ce atoms in apatite-type structure were established and promoted the regeneration of the catalyst and extended its lifecycle. Also, it was shown that the new composite had a high removal efficiency of TC in ozone catalytic degradation. In addition, the pathways and mechanism of TC degradation were proposed, and had a good stability performance after the reaction.

\section{Experimental and Methods}

A traditional high temperature solid-state reaction was used to prepare the $\mathrm{Mn}_{3} \mathrm{Gd}_{7-x} \mathrm{Ce}_{x}\left(\mathrm{SiO}_{4}\right)_{6} \mathrm{O}_{1.5}$ compounds. The raw materials including $\mathrm{MnCO}_{3}$ (Aldrich, 99.9\%), $\mathrm{SiO}_{2}$ (Aldrich, 99.9\%) and $\mathrm{Gd}_{2} \mathrm{O}_{3}$ (Aldrich, 99.99\%) and $\mathrm{CeO}_{2}$ (Aldrich, 99.99\%) used for the syntheses of $\mathrm{Mn}_{3} \mathrm{Gd}_{7-x} \mathrm{Ce}_{x}\left(\mathrm{SiO}_{4}\right)_{6} \mathrm{O}_{1.5}$ were purchased from the the Sinopharm Chemical Reagent Co., Ltd. Firstly, calculating the amount of each raw material required according to the stoichiometric ratio, after weighting and thoroughly mixing in the agate mortar, the mixtures were placed into little corundum crucibles, and covered with activated carbon to prevent oxidation. Finally, the samples were sintered at $1200^{\circ} \mathrm{C}$ for $4 \mathrm{~h}$ in muffle furnace to produce the final products.

The crystal structures of the synthesized samples were examined by the X-ray powder diffractometer $(\mathrm{XRD}$; D8 Advance diffractometer, Germany) with $\mathrm{CuK} \alpha$ radiation $(\lambda=1.5418 \AA)$ from $10^{\circ}$ to $70^{\circ}(2 \theta)$. The valence of manganese and cerium in the structure of $\mathrm{Mn}_{3} \mathrm{Gd}_{7-x} \mathrm{Ce}_{x}\left(\mathrm{SiO}_{4}\right)_{6} \mathrm{O}_{2}$ was confirmed by X-ray Photoelectron Spectroscopy (XPS, Thermo Scientific) with monochromatic AlKa irradiation (150 W). The binding energy (BE) scale was calibrated in reference ${ }^{23}$ to the energy of the adventitious carbon $(\mathrm{C} 1 \mathrm{~s})$ core level assigned at $284.6 \mathrm{eV}$. The visible spectra of as-prepared samples were performed on ultraviolet-visible spectroscopy (Beijing North Temple Instrument Technology Co., Ltd.) to collect the wavelength range from 500 to $700 \mathrm{~nm}$ at an interval of $1 \mathrm{~nm}$. The molecular weight of the obtained samples was identified by methods of HPLC-mass spectrometer (LC-MS. Thermo Scientific) with high resolution search (Thermo Scientific) ${ }^{24}$. Catalytic ozonation processes were carried out in a semi-batch reactor containing $0.4 \mathrm{~g} / \mathrm{L}$ of the target pollutant. The experimental device is composed of an ozone generating device, a vapor-liquid reaction device, a stirring device and an exhausting gas treating device. Ozone was produced by an ozone generator and passed into the reaction unit at $500 \mathrm{~cm}^{3} \bullet \mathrm{min}^{-1}$, and the concentration of ozone is $40 \mathrm{mg} / \mathrm{L}$. The reaction vessel was a $500 \mathrm{~mL}$ three-necked flask, the temperature in the vessel was maintained at $20^{\circ} \mathrm{C}$, and the agitation rate was set at $500 \mathrm{rpm} \bullet \mathrm{min}^{-1}$. The exhaust gas treatment unit is a $500 \mathrm{~mL} 25 \mathrm{~g} / \mathrm{L} \mathrm{Na}_{2} \mathrm{~S}_{2} \mathrm{O}_{3}$ solution. At certain time intervals, water samples were withdrawn from the reactor with a syringe and collected to measure the TC concentration. To test the stability and recyclability of $\mathrm{Mn}_{3} \mathrm{Gd}_{7-x} \mathrm{Ce}_{x}\left(\mathrm{SiO}_{4}\right)_{6} \mathrm{O}_{1.5}$, the catalyst was filtered, centrifuged at $10,000 \mathrm{rpm}$, dried at $80^{\circ} \mathrm{C}$, and used again in another cycles. 


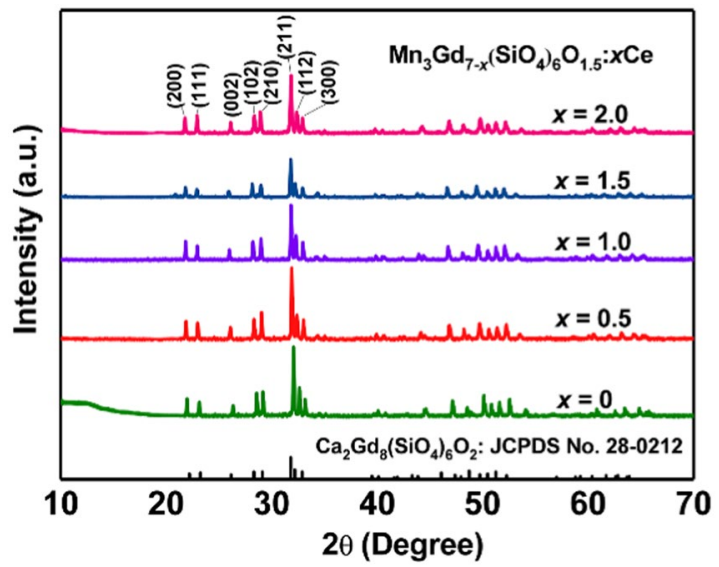

Figure 1. $\mathrm{XRD}$ patterns of $\mathrm{Mn}_{3} \mathrm{Gd}_{7-x}\left(\mathrm{SiO}_{4}\right)_{6} \mathrm{O}_{1.5}: x$ Ce particles, and the standard data for $\mathrm{Gd}_{2} \mathrm{Gd}_{8}\left(\mathrm{SiO}_{4}\right)_{6} \mathrm{O}_{2}$ (JCPDS card No. 28-0212) is shown as a comparison.
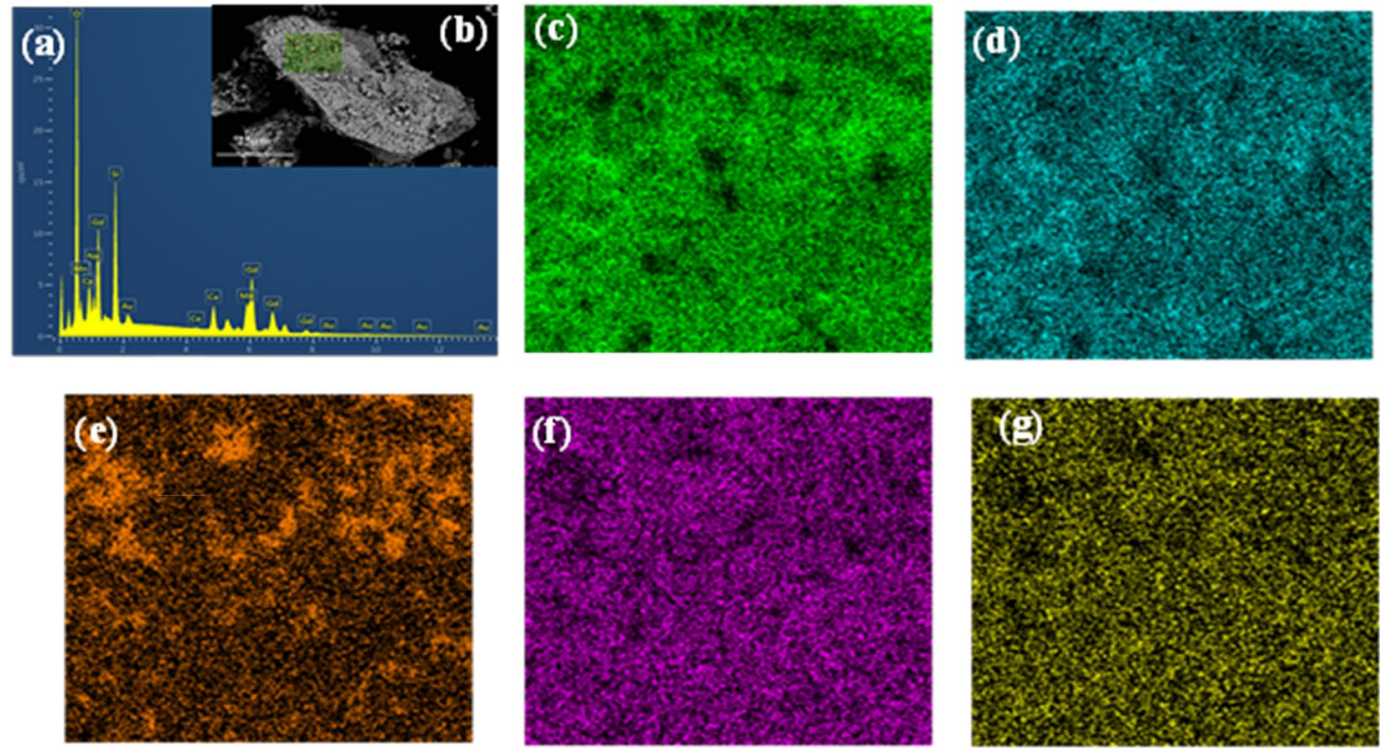

Figure 2. Catalyst on the degradation of TC, cycle stability test: (a) five times cycles, (b) XRD test of catalyst after every times using; leaching amount test: (c) leaching amount of Ce before and after recycle.

\section{Results and Discussion}

Characterization of the materials. Figure 1 shows the XRD patterns of the structure of $\mathrm{Mn}_{3} \mathrm{Gd}_{7-}$ ${ }_{x} \mathrm{Ce}_{x}\left(\mathrm{SiO}_{4}\right)_{6} \mathrm{O}_{1.5}$ solid solution along the $c$ axis. Two cationic sites exist in the structure: 9-fold coordinated $4 f$ sites with $\mathrm{C}_{3}$ point symmetry and 7 -fold coordinated $6 \mathrm{~h}$ sites with $C_{\mathrm{s}}$ point symmetry ${ }^{18}$. To verify the phase purity and structure, $\mathrm{Mn}_{3} \mathrm{Gd}_{7-x} \mathrm{Ce}_{x}\left(\mathrm{SiO}_{4}\right)_{6} \mathrm{O}_{1.5}$ with different amount cerium doping were characterized by XRD. The pure phases of the solid solution were obtain, and no peaks of other impurity phases were found. All the characterized peaks are in a good agreement with the standard $\mathrm{Ca}_{2} \mathrm{Gd}_{8}\left(\mathrm{SiO}_{4}\right)_{6} \mathrm{O}_{2}$ (JCPDS No.28-0212). Although the substitution amount of Ce element is increased, the structure of the compound remains isostructure with $\mathrm{Ca}_{2} \mathrm{Gd}_{8}\left(\mathrm{SiO}_{4}\right)_{6} \mathrm{O}_{2}$. Crucially, the proportion of positive ions was greater than that of negative ions in the sample, which provides direct evidence of the existence of vacancies ${ }^{25}$. Moreover, XRD patterns of the $\mathrm{Mn}_{3} \mathrm{Gd}_{7-x} \mathrm{Ce}_{x}\left(\mathrm{SiO}_{4}\right)_{6} \mathrm{O}_{1.5}$ samples after every cycles of TC degradation were shown in Fig. 2(b), and will be discussed in the following sections.

The Energy dispersive spectroscopy (EDS) were carried out for the chemical composition of the compounds prepared in the study. The result of a scanning electron microscope (SEM) image of a $\mathrm{Mn}_{3} \mathrm{Gd}_{5.5} \mathrm{Ce}_{1.5}\left(\mathrm{SiO}_{4}\right)_{6} \mathrm{O}_{1.5}$ sample was shown in Fig. 3(a). The particles of the sample are not uniform and the particles are relatively large due to agglomeration during heating. Figure 3(b) shows an EDS elemental analysis of surface points in a rectangular region, the proportion of positive-charged ions was greater than that of negative ions in the sample, which provides direct evidence of the existence of vacancies ${ }^{25}$. In addition, Fig. 3(c-g) shows the elemental distributions of $\mathrm{O}, \mathrm{Si}, \mathrm{Mn}, \mathrm{Gd}$, and $\mathrm{Ce}$ in $\mathrm{Mn}_{3} \mathrm{Gd}_{5.5} \mathrm{Ce}_{1.5}\left(\mathrm{SiO}_{4}\right)_{6} \mathrm{O}_{1.5}$ particles. The Mn element is less homogeneous than the 

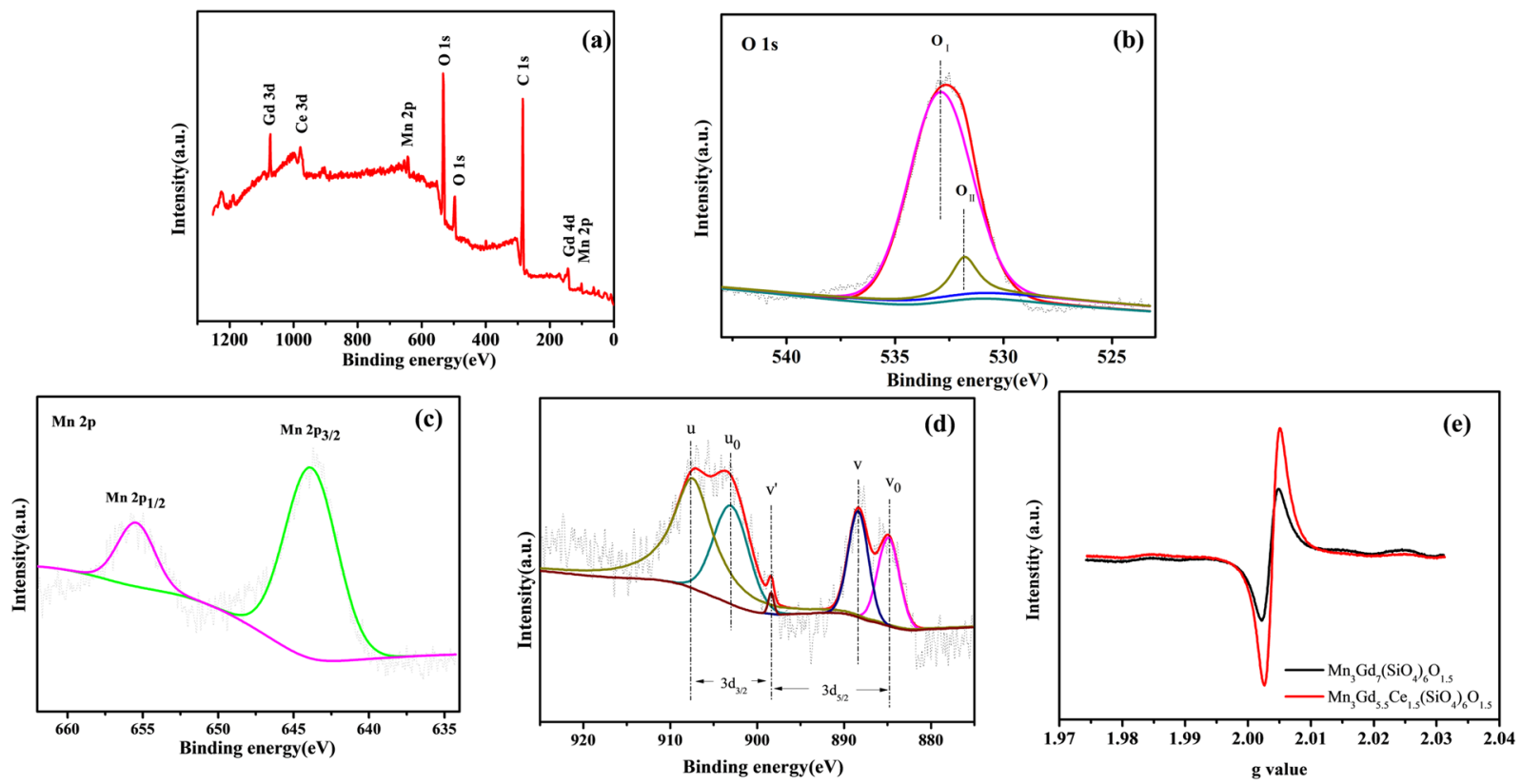

Figure 3. (a) EDS spectrum, (b) SEM image, (c-g)Elemental analysis of $\mathrm{Mn}_{3} \mathrm{Gd}_{5.5} \mathrm{Ce}_{1.5}\left(\mathrm{SiO}_{4}\right)_{6} \mathrm{O}_{1.5}$ particles about $\mathrm{O}, \mathrm{Si}, \mathrm{Mn}, \mathrm{Gd}$, and Ce respectively.

remaining elements, we think this might be due to the morphology of the samples and an increased amount near the surface of the particles.

To investigate the chemical states of the variable elements and oxygen in the sample, a wide survey scan of XPS spectra was carried out. All peaks have been corrected by C1s peaks position $(284.8 \mathrm{eV})^{26}$. Figure 4 (a) shows the XPS survey spectrum of $\mathrm{Mn}_{3} \mathrm{Gd}_{7-x} \mathrm{Ce}_{x}\left(\mathrm{SiO}_{4}\right)_{6} \mathrm{O}_{15}$. The presence of $\mathrm{Mn}, \mathrm{Gd}, \mathrm{Ce}, \mathrm{Si}, \mathrm{O}$, and $\mathrm{C}$ in Fig. 4(a), with no other impurity was detected. The high resolution XPS scan of the Mn2p doublet with the peak deconvolution is shown in Fig. 4(c). Both the peaks of Mn could well attach to the Mn 2p3/2 and Mn 2p1/2 at the binding energies (BE) of $642.5 \mathrm{eV}$ and $653.4 \mathrm{eV}$. There was no any noticeable shoulder peaks observed in Mn2p spectra of $\mathrm{Mn}_{3} \mathrm{Gd}_{7-x} \mathrm{Ce}_{x}\left(\mathrm{SiO}_{4}\right)_{6} \mathrm{O}_{1.5}$, revealing that $\mathrm{Mn}$ ions are in the formal chemical valance state of $2+$. Analysis of the Ce $3 \mathrm{~d}$ spectra showed that $903.5 \mathrm{eV}\left(\mathrm{U}_{0}\right), 898.8 \mathrm{eV}\left(\mathrm{V}^{\prime}\right)$, and $884.9 \mathrm{eV}\left(\mathrm{V}_{0}\right)$ were ascribed to $\mathrm{Ce}^{3+}$ species while $907.5 \mathrm{eV}(\mathrm{U})$ and $888.2 \mathrm{eV}(\mathrm{V})$ were attributed to $\mathrm{Ce}^{4+}$ species (Fig. $4(\mathrm{~d})$ ). The surface concentration of $\mathrm{Ce}^{4+}$ can be determined by $\mathrm{Ce}^{4+}=\mathrm{Ce}^{4+} /\left(\mathrm{Ce}^{4+}+\mathrm{Ce}^{3+}\right) ; \mathrm{Ce}^{3+}=\mathrm{Ce}^{3+} /\left(\mathrm{Ce}^{4+}+\mathrm{Ce}^{3+}\right)$, where $\mathrm{Ce}^{3+}=\mathrm{U}_{0}+\mathrm{V}^{\prime}+\mathrm{V}_{0}$ and $\mathrm{Ce}^{4+}=\mathrm{U}+\mathrm{V}$. Inherent challenges are present for Ce $3 \mathrm{~d}$ XPS spectrum analysis because of the difficulty in deconvolution of individual peaks in $\mathrm{Ce} 3 \mathrm{~d} 3 / 2$ and $\mathrm{Ce} 3 \mathrm{~d} 5 / 2$ envelopes ${ }^{27}$. So the proportion of $\mathrm{Ce}^{4+}$ and $\mathrm{Ce}^{3+}$ was $55 \%$ and $45 \%$ in the composite ${ }^{28}$. In order to confirm the oxygen vacancies in the prepared samples, we analyzed the XPS spectra of O1s. The result of O1s BE peaks of $\mathrm{Mn}_{3} \mathrm{Gd}_{5.5} \mathrm{Ce}_{1.5}\left(\mathrm{SiO}_{4}\right)_{6} \mathrm{O}_{1.5}$ have been showed in Fig. 4(b). The $\mathrm{O} 1 \mathrm{~s}$ XPS spectra were deconvoluted with three major peaks, located at $529.9 \mathrm{eV}, 531.8 \mathrm{eV}$, and $532.6 \mathrm{eV}$, which correspond to lattice oxygen species $\left(\mathrm{O}_{2}^{-}\right)$named $\mathrm{O}_{\mathrm{I}}$ and adsorbed oxygen (e.g., $\mathrm{O}_{2}{ }^{2-}$ and $\mathrm{O}^{-}$), and hydroxyl groups $\left(\mathrm{OH}^{-}\right)$, respectively ${ }^{29}$ named $\mathrm{O}_{\text {II }}$. The atom ratio of $\mathrm{O}_{\text {I }}$ to $\mathrm{O}_{\text {II }}$ was 4.02 for $\mathrm{Mn}_{3} \mathrm{Gd}_{5.5} \mathrm{Ce}_{1.5}\left(\mathrm{SiO}_{4}\right)_{6} \mathrm{O}_{1.5}$, which is higher than that of $\mathrm{Mn}_{3} \mathrm{Gd}_{7}\left(\mathrm{SiO}_{4}\right)_{6} \mathrm{O}_{1.5}$ to 3.17, respectively, indicating that the doping of Ce increased the oxygen defects of $\mathrm{Mn}_{3} \mathrm{Gd}_{7}\left(\mathrm{SiO}_{4}\right)_{6} \mathrm{O}_{1.5}$, which is the most active oxygen, and has been reported to play an important role in the oxidation reaction ${ }^{30}$. Otherwise, the EPR comparative experiment of $\mathrm{Mn}_{3} \mathrm{Gd}_{7}\left(\mathrm{SiO}_{4}\right)_{6} \mathrm{O}_{1.5}$ and $\mathrm{Mn}_{3} \mathrm{Gd}_{5.5} \mathrm{Ce}_{1.5}\left(\mathrm{SiO}_{4}\right)_{6} \mathrm{O}_{1.5}$ is shown in Fig. 4(e). Obviously, the peaks of $\mathrm{Mn}_{3} \mathrm{Gd}_{5.5} \mathrm{Ce}_{1.5}\left(\mathrm{SiO}_{4}\right)_{6} \mathrm{O}_{1.5}$ is higher than that of $\mathrm{Mn}_{3} \mathrm{Gd}_{7}\left(\mathrm{SiO}_{4}\right)_{6} \mathrm{O}_{1.5}$, also verifing that the doping of $\mathrm{Ce}$ increases the oxygen vacancies, increases the activity of the catalyst.

Catalytic degradation of TC in $\mathrm{Mn}_{3} \mathrm{Gd}_{7-x} \mathrm{Ce}_{x}\left(\mathrm{SiO}_{4}\right)_{6} \mathrm{O}_{1.5}$ system. Degradation processes of TC using $\mathrm{Mn}_{3} \mathrm{Gd}_{7-x} \mathrm{Ce}_{x}\left(\mathrm{SiO}_{4}\right)_{6} \mathrm{O}_{1.5}$ as a catalyst were investigated in the presence of ozone, (Experimental conditions: Catalyst loading $2 \mathrm{~g} \mathrm{~L}^{-1}, \mathrm{pH}=3.4$ working volume of $200 \mathrm{~mL},[\mathrm{TC}]_{0}=400 \mathrm{mg} \mathrm{L}^{-1}$, the concentration of ozone is $40 \mathrm{mg} / \mathrm{L}$ ). Figure 5(a) shows the comparisons of time-dependent reaction yields between the ozonation and the six catalysts (the situation under which ozone alone as a control is also included). First of all, when only the $\mathrm{Mn}_{3} \mathrm{Gd}_{5.5} \mathrm{Ce}_{1.5}\left(\mathrm{SiO}_{4}\right)_{6} \mathrm{O}_{1.5}$ compound was added into the TC solution, there was no adsorption of TC. It is obvious that there are substantially different performances in the catalytic oxidation of TC. The composite $\mathrm{Mn}_{3} \mathrm{Gd}_{5.5} \mathrm{Ce}_{1.5}\left(\mathrm{SiO}_{4}\right)_{6} \mathrm{O}_{1.5}$ has the greater catalytic capability for TC degradation in comparison with pure $\mathrm{Mn}_{3} \mathrm{Gd}_{7}\left(\mathrm{SiO}_{4}\right)_{6} \mathrm{O}_{1.5}$. So, $\mathrm{Mn}_{3} \mathrm{Gd}_{7}\left(\mathrm{SiO}_{4}\right)_{6} \mathrm{O}_{1.5}$ was mixed with $\mathrm{CeO}_{2}$, and $\mathrm{MnO}_{2}$. It could be observed, that the introduction of $\mathrm{Ce}$ enhanced the catalytic degradation efficiency. To further investigate the impact of $\mathrm{Ce}$, different amounts of Ce doped $\mathrm{Mn}_{3} \mathrm{Gd}_{7-x} \mathrm{Ce}_{x}\left(\mathrm{SiO}_{4}\right)_{6} \mathrm{O}_{1.5}$ samples was prepared, and used in the catalytic degradation of TC. As shown in Fig. 5(b), increasing of the Ce doping concentration from $0 \%$ to $15 \%$ led to a significant increase of TC removal, implying that the cerium doping plays an important role in catalytic ozonation as an 
(a)
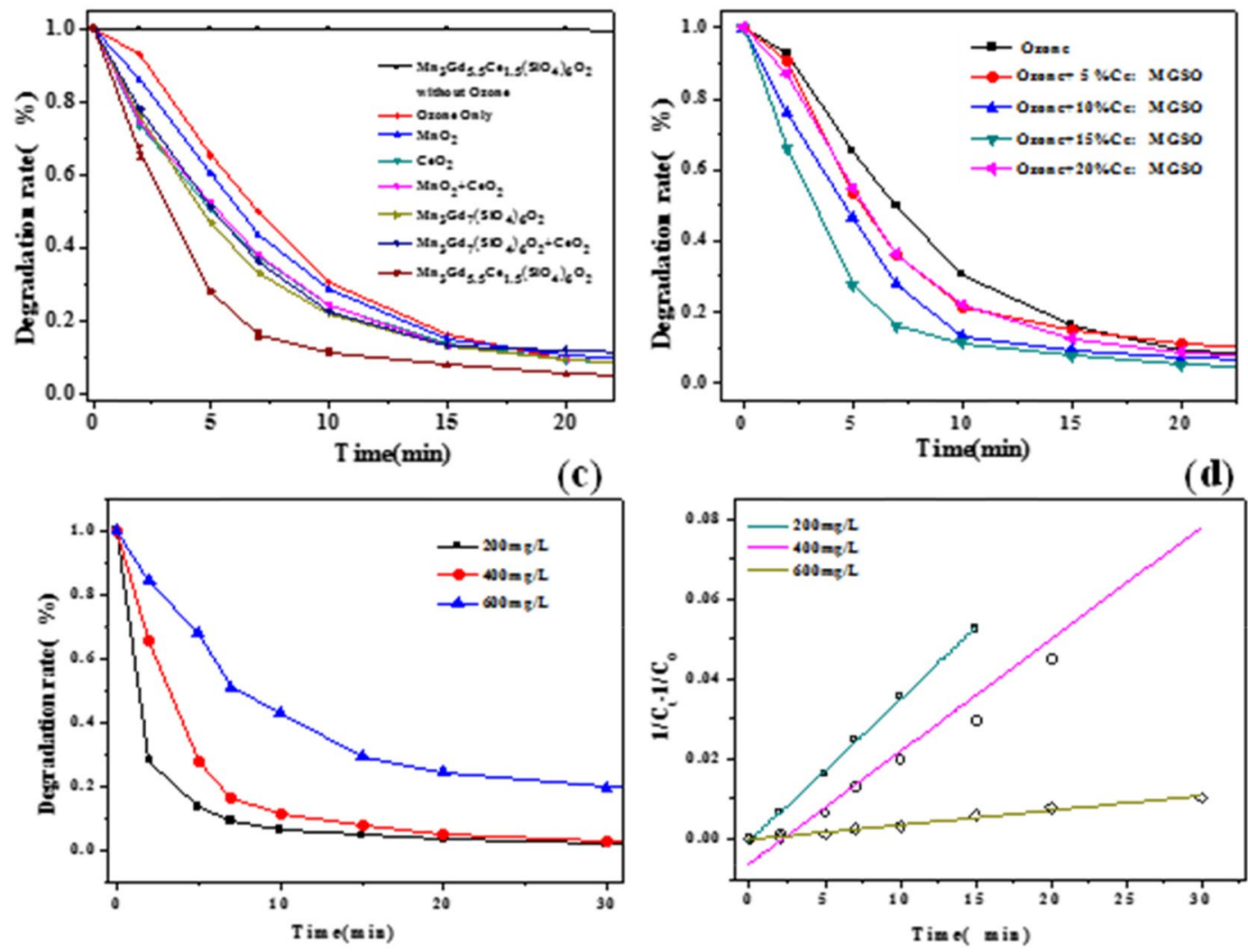

Figure 4. (a) XPS spectra of $\mathrm{Mn}_{3} \mathrm{Gd}_{7-x} \mathrm{Ce}_{x}\left(\mathrm{SiO}_{4}\right)_{6} \mathrm{O}_{1.5}$ synthesized in present work. (b) high resolution XPS spectra at $\mathrm{O} 1 \mathrm{~s}$ position of compounds. (c) $\mathrm{Mn} 2 \mathrm{p}$. position of $\mathrm{Mn}_{3} \mathrm{Gd}_{7-x} \mathrm{Ce}_{x}\left(\mathrm{SiO}_{4}\right)_{6} \mathrm{O}_{1.5}$ (d) Ce 3d. position of $\mathrm{Mn}_{3} \mathrm{Gd}_{7-x} \mathrm{Ce}_{x}\left(\mathrm{SiO}_{4}\right)_{6} \mathrm{O}_{1.5} ;\left(\right.$ e) Comparative EPR spectra of $\mathrm{Mn}_{3} \mathrm{Gd}_{7}\left(\mathrm{SiO}_{4}\right)_{6} \mathrm{O}_{1.5}$ and $\mathrm{Mn}_{3} \mathrm{Gd}_{5.5} \mathrm{Ce}_{1.5}\left(\mathrm{SiO}_{4}\right)_{6} \mathrm{O}_{1.5}$ particles.

active species. When the amount of cerium doping continuously increased up to $20 \%$, the efficiency reduces. That can be explain that when the doping amount is $15 \%,(211)$ crystal plane of the compound has the lowest crystal strength, resulting in increased defects and active sites. So the most suitable proportion of Ce doped amount in $\mathrm{Mn}_{3} \mathrm{Gd}_{7-x} \mathrm{Ce}_{x}\left(\mathrm{SiO}_{4}\right)_{6} \mathrm{O}_{1.5}$ is $x=1.5$ for catalytic ozonation of TC.

For ozonation catalyst process, initial TC concentration is a worth considering parameter. The experiments of different TC concentration were conducted, the result in Fig. 5(c) shows that the degradation efficiency of TC dropped with increasing of initial concentrations. When the concentration rises from $200 \mathrm{mg} / \mathrm{L}$ to $600 \mathrm{mg} / \mathrm{L}$, the degradation efficiency dropped from $99.8 \%$ to $86.2 \%$. The excess of TC (up to $600 \mathrm{mg} / \mathrm{L}$ ) or its degradation intermediates may need to consume more active radicals, so the catalytic capability became slight low. Additionally, the mechanism of TC degradation under the catalysis of $\mathrm{Mn}_{3} \mathrm{Gd}_{5.5} \mathrm{Ce}_{1.5}\left(\mathrm{SiO}_{4}\right)_{6} \mathrm{O}_{1.5}$ was explored under different initial TC concentration $(200,400$ and $600 \mathrm{mg} / \mathrm{L})$ according to the pseudo-first order and pseudo-second order kinetics ${ }^{31}$.

$$
\begin{gathered}
\text { Pseudo-first order kinetic: } \ln \left(C_{0} / C_{t}\right)=k_{1} \mathrm{t} \\
\text { Pseudo-second order kinetic: } 1 / C_{t}-1 / C_{0}=k_{2} \mathrm{t}
\end{gathered}
$$

where $C_{0}$ is the initial concentration of TC, $C_{t}$ is the concentration of the TC in the solution after treatment at time $t$, and $k_{1}$ and $k_{2}$ are pseudo-first and pseudo-second order rate constants. Clearly, the degradation of TC was better described by the pseudo-second order kinetic model ${ }^{17}$ judged by its regression coefficient $\left(R^{2}>0.96\right)$. The fitting result are shown in Fig. 5(d), as the concentration increased from 200 to $600 \mathrm{mg} / \mathrm{L}$ the reaction rate constants $k_{2}$ were $0.0036,0.0028$ and $0.0004 \mathrm{Lmg}^{-1} \mathrm{~min}^{-1}$, respectively.

Possible degradation mechanism in the presence of $\mathrm{Mn}_{3} \mathrm{Gd}_{5.5} \mathrm{Ce}_{1.5}\left(\mathrm{SiO}_{4}\right)_{6} \mathrm{O}_{1.5}$ catalyst. During TC degradation with catalysts under ozone as oxidant, several kinds of reactive radicals, such as $\cdot \mathrm{OH}$, and $\cdot \mathrm{O}_{3}$, could be generated and have a great influence under the activation of transition metals. In order to investigate the effect of the two reactive radicals, benzoquinone and IPA were added into the TC solutions to scavenge these radicals. Benzoquinone is widely used to quench $\mathrm{O}_{2}^{-}$, and IPA usually used to scavenge $\cdot \mathrm{OH}$. After $5 \mathrm{~min}$ of reaction, $1 \mathrm{mmol}$ IPA was added to the solution, the amount of TC degradation declined from $289 \mathrm{mg} / \mathrm{L}$ to $241 \mathrm{mg} / \mathrm{L}$ 
(a)

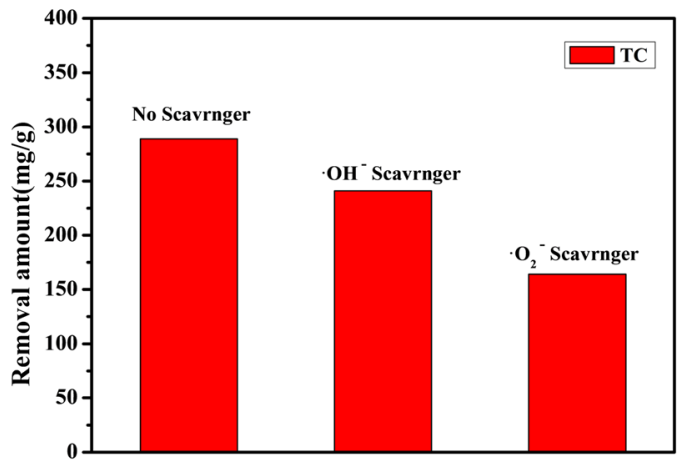

(c)

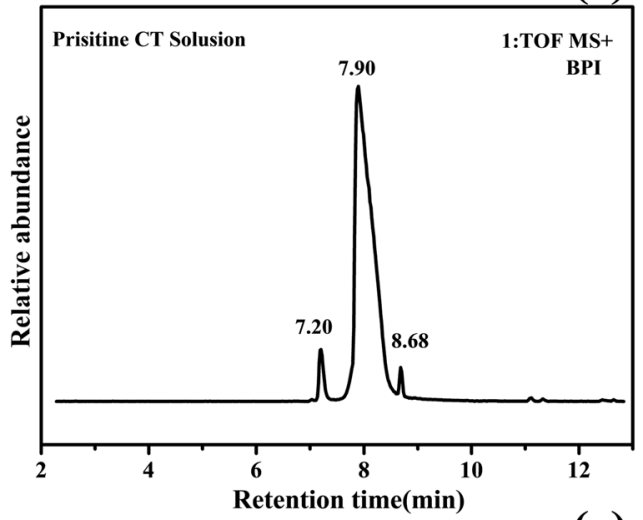

(e)

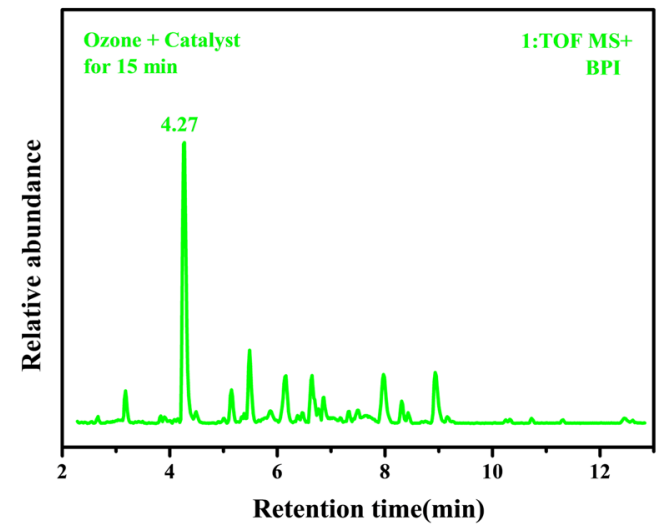

(b)

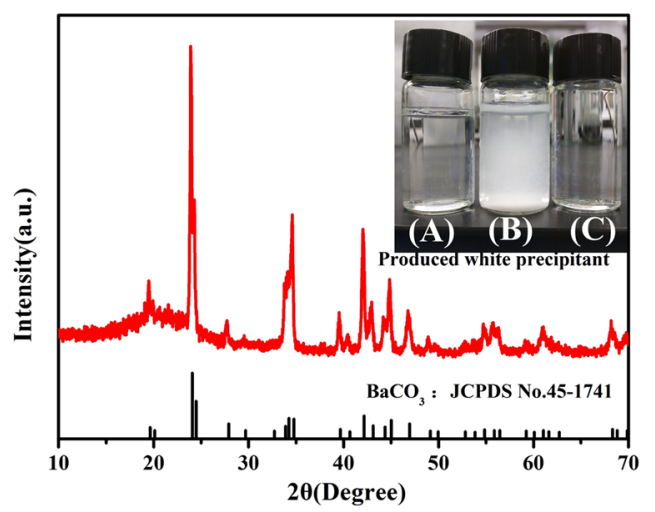

(d)

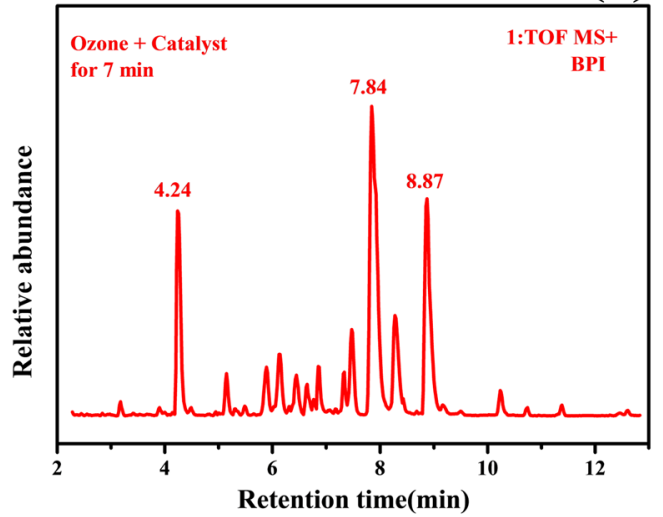

(f)

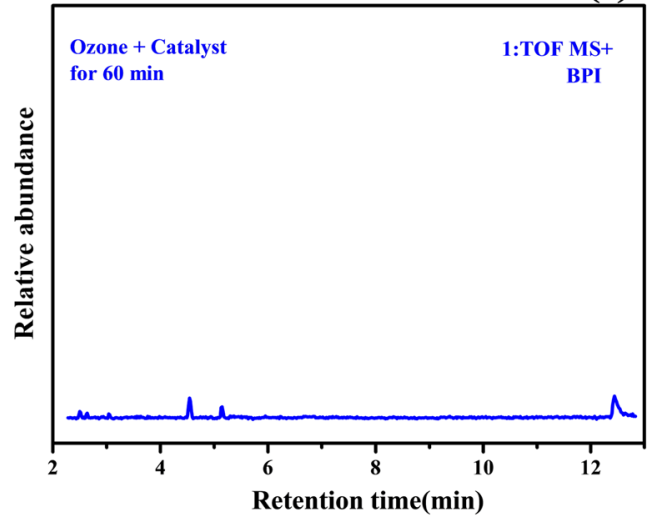

Figure 5. The catalytic catalystic degradation behavior of TC (Experimental conditions: Catalyst loading $2.5 \mathrm{~g}$, $\mathrm{pH}=3.4),[\mathrm{TC}]_{0}=400 \mathrm{mg} \mathrm{L}^{-1}$, working volume $=200 \mathrm{~mL}$, and its degradation behavior under $\mathrm{O}_{3} /$ Catalyst system, the concentration of ozone is $40 \mathrm{mg} / \mathrm{L}$.) (a)different forms of manganese and cerium (b) different doping amount of cerium in the catalytic system (c)different initial concentrations in catalystic system (d) Pseudo-second order kinetic behavior under different tetracycline concentration in degradation process.

(Fig. 6(a)). When the same excess amount of benzoquinone was added, the TC removal dropped to $164 \mathrm{mg} / \mathrm{L}$. The competitive radical tests suggest superoxide is the dominating active radicals in the degradation of TC using $\mathrm{Mn}_{3} \mathrm{Gd}_{5.5} \mathrm{Ce}_{1.5}\left(\mathrm{SiO}_{4}\right)_{6} \mathrm{O}_{1.5}$ as a catalyst. Nevertheless, the results of the scavenger experiments proved that $\cdot \mathrm{OH}$ also participated in the catalytic ozonation, the combination of the two reactive radicals leads to the efficient reaction.

To confirm the catalytic effect of the $\mathrm{Ce}^{3+}$-doped composite, a couple of comparable experiments have been made. The catalytic degradation of TC using $\mathrm{Mn}_{3} \mathrm{Gd}_{5.5} \mathrm{Ce}_{1.5}\left(\mathrm{SiO}_{4}\right)_{6} \mathrm{O}_{1.5}$ had a great efficiency than any others (Fig. 3(b)). Obviously, Ce made the difference in the process, as the XPS test showed Ce was made by a mixture of positive tri- and tetra-valent cations. $\mathrm{Ce}^{3+} / \mathrm{Ce}^{4+}$ is a good indicator for the redox reaction and development of superoxide free radicals ${ }^{32}$.

According to the above result, degradation reaction should occur on the catalyst surface via Ce due to its redox capability ${ }^{11}$. First, $\mathrm{S} \equiv \mathrm{Ce}^{3+}$ could react with $\mathrm{O}_{3}$, with the electron transferring, superoxide and oxygen were 
(a)

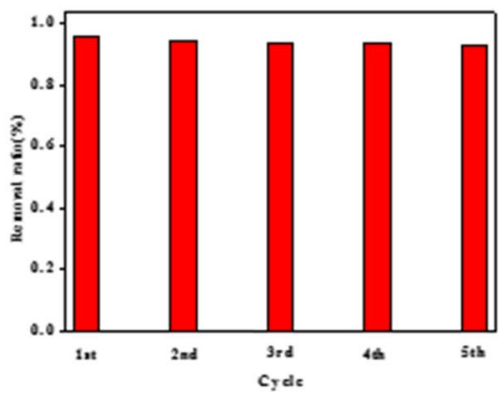

(b)

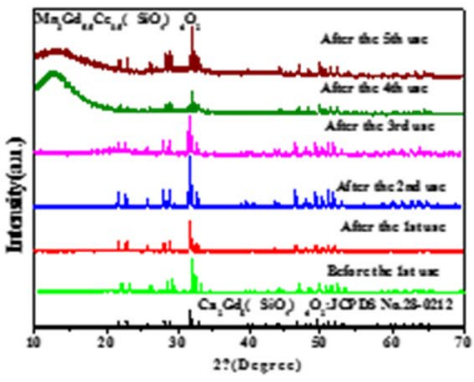

(c)

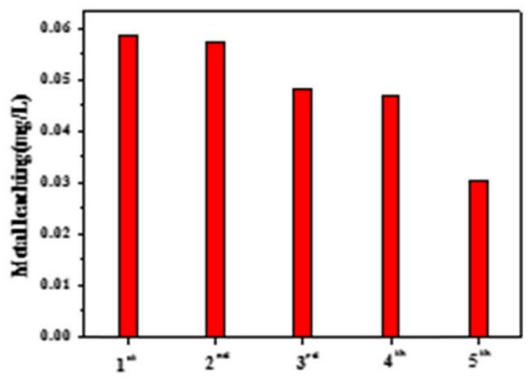

Figure 6. (a) The effects of different scavengers on the degradation of $\mathrm{TC}$ and with $\mathrm{Mn}_{3} \mathrm{Gd}_{5.5} \mathrm{Ce}_{1.5}\left(\mathrm{SiO}_{4}\right)_{6} \mathrm{O}_{1.5}$ catalyst under $\mathrm{O}_{3}$, (b) XRD patterns of the white precipitation formed in $\mathrm{Ba}(\mathrm{OH})_{2}$ solutions, Insert: picture of $\mathrm{Ba}(\mathrm{OH})_{2}$ solutions after treatment. Gas produced by TC degradation with $\mathrm{O}_{3}(\mathrm{~A})$ and gas produced by catalytic degradation passed through the $\mathrm{Ba}(\mathrm{OH})_{2}$ solutions.(B), several $2 \mathrm{~mol} / \mathrm{L} \mathrm{HCl}$ was added(C), High-performance liquid chromatography of TC (c), the degradation process for $7 \mathrm{~min}(\mathbf{d}), 15 \mathrm{~min}(\mathbf{e})$, and $60 \mathrm{~min}(\mathbf{f})$.

produced ${ }^{32,33}$ (Eq. 3). Then the obtained $\mathrm{O}_{2}{ }^{-}$continues to react with another $\mathrm{O}_{3}$ to produce a peroxide $\left(\mathrm{O}_{2}{ }^{2-}\right)$ molecule and a dioxygen molecule (Eq. 4). $\mathrm{O}_{2}{ }^{2-}$ molecule would react with $\mathrm{S} \equiv \mathrm{Ce}^{4+}$ in turn to produce $\mathrm{Ce}^{3+}$ (Eq. 5). The oxygen-containing reactive intermediate reacts with tetracycline which is also adsorbed on the surface of the catalyst ${ }^{33}$.

$$
\begin{gathered}
\mathrm{O}_{3}+\mathrm{S} \equiv \mathrm{Ce}^{3+}+\cdot \mathrm{OH} \rightarrow \mathrm{S} \equiv \mathrm{Ce}^{4+}+\mathrm{O}_{2}+\mathrm{O}^{2-} \\
\mathrm{O}_{3}+\mathrm{O}^{2-} \rightarrow \mathrm{O}_{2}+\mathrm{O}_{2}^{2-} \\
\mathrm{O}_{2}{ }^{2-}+\mathrm{S} \equiv \mathrm{Ce}^{4+} \rightarrow \mathrm{O}_{2}+\mathrm{S} \equiv \mathrm{Ce}^{3+}
\end{gathered}
$$

As reported by Jia et al. ${ }^{34}$, the react active site would be made up of the oxygen vacancy site on the catalyst surface, when catalyst was attacked by ozone, one of $\mathrm{O}$ atom of $\mathrm{O}_{3}$ could insert into oxygen vacancy site. Electrons transfer will easy occur in oxygen vacancies to transfer electrons to an ozone molecule, the result is obtaining a new surface bound oxygen species $\left(\mathrm{O}^{2-}\right)$ and dioxygen molecule at original oxygen vacancy site, which leads to be a gas phase (Eq. 6). The following step is that another ozone molecule will react with the surface bounded $\mathrm{O}^{2-}$ to form a dioxygen and the second peroxide $\left(\mathrm{O}_{2}{ }^{2-}\right)$ molecule (Eq. 7). Finally, the peroxide species was unstable and decomposes to a dioxygen and then recover the initial oxygen vacancy to join the following ozonolysis cycle ${ }^{33}$. The key point of catalysis process is to decompose the peroxide in time to make sure the oxygen vacancies recover that the peroxide can easy transfer the lattice oxygen to improve the catalyst activity ${ }^{33,34}$.

$$
\begin{gathered}
\mathrm{O}_{3}+\mathrm{V}_{\mathrm{o}} \rightarrow \mathrm{O}_{2}+\mathrm{O}^{2-} \\
\mathrm{O}^{2-}+\mathrm{O}_{3} \rightarrow \mathrm{O}_{2}+\mathrm{O}_{2}{ }^{2-} \\
\mathrm{O}_{2}^{2-} \rightarrow \mathrm{O}_{2}+\mathrm{V}_{\mathrm{o}}
\end{gathered}
$$

In order to further investigate the degradation process and intermediate compounds produced during reaction the HPLC-MS technology was applied. The results of the TC solution $(400 \mathrm{mg} / \mathrm{L})$ chromatography after different reaction time with the presence of the catalyst are illustrated in Fig. 6 . The identification was based on mass fragmentation values and by comparing the mass spectra to a database. It is apparent, that the relative intensity of the ion $[1+\mathrm{H}]^{+}$of $\mathrm{m} / \mathrm{z} 445$ decreases with the reaction proceeds, whereas two new and intense ions with $461 \mathrm{~m} / \mathrm{z}$ and $477 \mathrm{~m} / \mathrm{z}$ are clearly detected. This means that the degradation reaction of TC solution continuously occurred. As the reaction proceeds three kinds of functional groups (double bond, amine group, and phenolic groups) of TC will compete for the ozone.

The results of the HPLC-MS indicate that fragmentations of TC yielded ions with an $\mathrm{m} / \mathrm{z}$ value of 427 on the loss of $\mathrm{NO}_{3}{ }^{-}$, which further fragmented to the ions with the value $410 \mathrm{~m} / \mathrm{z}$ on the $\mathrm{H}_{2} \mathrm{O}$ loss ${ }^{35}$. After 60 minutes of ozone catalytic degradation, there was still a small amount of compounds present (molecules with $114 \mathrm{~m} / \mathrm{z}$ value were detected) (Fig. 6(d)).

However, the exact structures of these compounds could not be identified in the present study and further work still required for a more detailed structures analysis. In addition to these results, we also detected the exhausted gas generated during the degradation process, and the exhaust gas was introduced into the clarified saturated $\mathrm{Ba}(\mathrm{OH})_{2}$ solution as shown in the insert (A) in Fig. 6(b). It can be clearly observed that the transparent solution inset (A) Fig. 6(b) became cloudy inset (B) Fig. 6(b), and a certain amount of white precipitate was formed at the bottom of the bottle. When the excess dilute hydrochloric acid was added dropwise to the 


\begin{tabular}{|l|l|l|l|}
\hline method & Reaction conditions & Degradation & ref. \\
\hline $\mathrm{Mn}_{3} \mathrm{Gd}_{7-x} \mathrm{Ce}_{\mathrm{x}}\left(\mathrm{SiO}_{4}\right)_{6} \mathrm{O}_{2} / \mathrm{O}_{3}$ & $\begin{array}{l}{[\mathrm{TC}]=400 \mathrm{mg} / \mathrm{L}} \\
{[\text { Catalyst }]=2.5 \mathrm{~g} / \mathrm{L}}\end{array}$ & $\begin{array}{l}95 \% \\
20 \mathrm{~min} \\
99 \% \\
60 \mathrm{~min}\end{array}$ & This work \\
\hline $\begin{array}{l}\text { Adsorption using mesoporous BiOI } \\
\text { microspheres }\end{array}$ & {$[\mathrm{TC}]=40 \mathrm{mg} / \mathrm{L}$} & $\begin{array}{l}56 \% \\
360 \mathrm{~min}\end{array}$ & 25 \\
\hline $\begin{array}{l}\mathrm{US} / \mathrm{Fe}_{3} \mathrm{O}_{4} / \mathrm{H}_{2} \mathrm{O}_{2} \\
\text { Photocatalytic }\end{array}$ & {$[\mathrm{TC}]=100 \mathrm{mg} / \mathrm{L}$} \\
{$[$ Catalyst $]=2.0 \mathrm{~g} / \mathrm{L}$} & $\begin{array}{l}93.7 \% \\
60 \mathrm{~min}\end{array}$ & 26 \\
\hline Microwave induction & {$[\mathrm{TC}]=40 \mathrm{mg} / \mathrm{L}$} & $95 \%$ \\
{$[$ Catalyst $]=1.0 \mathrm{mg} / \mathrm{L}$} & $60 \mathrm{~min}$ & 27 \\
\hline & {$[\mathrm{TC}]=50 \mathrm{mg} / \mathrm{L}$} & $34.8 \%$ & 28 \\
\hline [Catalyst $]=2.0 \mathrm{~g} / \mathrm{L}$ & $30 \mathrm{~min}$ & \\
\hline
\end{tabular}

Table 1. Comparison of the degradation effects of different treating methods to remove tetracycline.

turbid solution, the cloudy disappeared and the solution became transparent again as shown in the insert (A) in Fig. 6(c). To identify the gained from the experience precipitate, it was collected from the bottom of the bottle and subjected to the XRD test. The XRD results are shown in the Fig. 6(b). The comparison with the card JCPDS no. 45-174 $\left(\mathrm{Ba}\left(\mathrm{CO}_{3}\right)_{2}\right)$ revealed that the obtained precipitate is exactly $\mathrm{Ba}\left(\mathrm{CO}_{3}\right)_{2}$. This result confirmed that the reaction to produce $\mathrm{CO}_{2}$ gas as the final product of the degradation reaction progress of the TC took place in the experiment. The above experimental phenomena follows the following two reaction equations:

$$
\begin{gathered}
\mathrm{CO}_{2}+\mathrm{Ba}(\mathrm{OH})_{2}=\mathrm{BaCO}_{3} \downarrow+\mathrm{H}_{2} \mathrm{O} \\
\mathrm{BaCO}_{3}+\mathrm{HCl}=\mathrm{BaCl}_{2}+\mathrm{H}_{2} \mathrm{O}+\mathrm{CO}_{2} \uparrow
\end{gathered}
$$

The degradation process proceeds through the formation of a series of mineralized intermediates, which then further oxidize to water, inorganic ions and carbon dioxide ${ }^{36}$. Based on these results. So, it can be concluded that TC is completely decomposed through the oxidation by $(\bullet \mathrm{OH})$ and $\left(\bullet \mathrm{O}^{2-}\right)$ after less than 30 min the presence of ozone. The overall degraded reaction can be supposed by the following equation:

$$
\mathrm{C}_{22} \mathrm{H}_{24} \mathrm{~N}_{2} \mathrm{O}_{8}+\mathrm{O}_{3} \rightarrow \mathrm{CO}_{2}+\mathrm{NO}_{3}^{-}+\mathrm{Cl}^{-}+\mathrm{H}_{2} \mathrm{O}
$$

Reusability and stability of $\mathrm{Mn}_{3} \mathrm{Gd}_{5.5} \mathrm{Ce}_{1.5}\left(\mathrm{SiO}_{4}\right)_{6} \mathrm{O}_{1.5}$ catalyst. For economic reasons, the capability of recycling $\mathrm{Mn}_{3} \mathrm{Gd}_{5.5} \mathrm{Ce}_{1.5}\left(\mathrm{SiO}_{4}\right)_{6} \mathrm{O}_{1.5}$ catalyst was evaluated. Figure 2(a) shows the results of catalyst after being used for five times (After each experiment, we used 10,000 rpm high speed centrifugation, and filtered the samples, then collected the samples, and dried at $80^{\circ} \mathrm{C}$ in an air oven). Comparing with the first use, the degradation rate decreased slightly during the first and the fifth reactions, but TC removal was almost the same. This indicates that the catalyst still remains active after consecutive runs. XRD results shows that there is no impurity in the structure after each reaction, so the catalyst can keep a great reusability (Fig. 2(b)).

The amount of metal leaching is also an important factor in measuring the stability of the catalyst. The excessive metal leaching can lead to deactivation of the catalyst. So, an ICP measurement was carried out to determine the concentrations of dissolved active Ce after the reaction (Fig. 2(c)). When the amount of the added catalyst was $0.5 \mathrm{~g}$ per $200 \mathrm{mg} / \mathrm{L}$ TC solution at $\mathrm{pH} 3.4$, the equilibrium concentrations of $\mathrm{Mn}, \mathrm{Gd}$, and Ce were $0.051,0.050$, and $0.086 \mathrm{mg} / \mathrm{L}$, respectively, after the reaction was completed for 60 minutes. The amount of leached metal did not affect the activity of the catalyst, since the atoms are stable present in the apatite structure. So, a stable apatite structure can be applied as a potential structural design unit to heterogeneously catalyzed oxidative degradation.

In recent years, there are many kinds of ways have been intensively studied to completely settle an issue of tetracycline pollution in water. A preliminary and brief comparison of the degradation effects of different treating methods ${ }^{37-41}$ to remove tetracycline is summarized in Table 1. Compared with the mentioned works, the as-synthesized $\mathrm{Mn}_{3} \mathrm{Gd}_{5.5} \mathrm{Ce}_{1.5}\left(\mathrm{SiO}_{4}\right)_{6} \mathrm{O}_{1.5}$ catalyst investigated in this study shows excellent performance for the degradation of tetracycline under ozone, and also shows outstanding reusability and stability.

\section{Conclusion}

In this paper, the $\mathrm{Mn}_{3} \mathrm{Gd}_{5.5} \mathrm{Ce}_{1.5}\left(\mathrm{SiO}_{4}\right)_{6} \mathrm{O}_{1.5}$ catalyst with the apatite-type structure was successfully prepared by traditional high temperature solid phase method. The catalyst exhibited good catalytic activity and stability for the degradation of TC at room temperature. This result could attribute to the synergistic effect between the different valence of the cerium ion. Free radical scavenging experiments proved that superoxide radicals were the most active substances in the reaction process, and, thus, suggested possible degradation pathways of TC in the reaction process. In summary, $\mathrm{Mn}_{3} \mathrm{Gd}_{5.5} \mathrm{Ce}_{1.5}\left(\mathrm{SiO}_{4}\right)_{6} \mathrm{O}_{1.5}$ is a promising catalyst for removal of $\mathrm{TC}$ in wastewater.

Received: 24 June 2019; Accepted: 24 November 2019;

Published online: 10 December 2019 


\section{References}

1. Wu, T. et al. Mechanistic insight into interactions between tetracycline and two iron oxide minerals with different crystal structures. Chemical Engineering Journal 366, 577-586, https://doi.org/10.1016/j.cej.2019.02.128 (2019).

2. Bai, C. X., Shen, F. \& Qi, X. H. Preparation of porous carbon directly from hydrothermal carbonization of fructose and phloroglucinol for adsorption of tetracycline. Chinese Chemical Letters 28, 960-962 (2017).

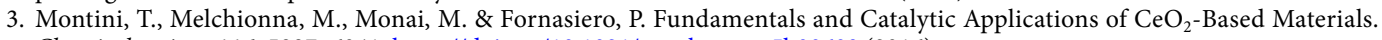
Chemical reviews 116, 5987-6041, https://doi.org/10.1021/acs.chemrev.5b00603 (2016).

4. Segura, P. A., François, M., Gagnon, C. \& Sauvé, S. Review of the Occurrence of Anti-infectives in Contaminated Wastewaters and Natural and Drinking Waters. Environmental Health Perspectives 117, 675-684 (2009).

5. Ismadji, S., Soetaredjo, F. E. \& Ayucitra, A. Natural Clay Minerals as Environmental Cleaning Agents. (Springer International Publishing, (2015).

6. Song, C. et al. Fate of tetracycline at high concentrations in enriched mixed culture system: biodegradation and behavior. Journal of Chemical Technology \& Biotechnology 91, 1562-1568 (2016).

7. Xiong, Z. Degradation of p-nitrophenol (PNP) in aqueous solution by a micro-size $\mathrm{Fe}^{0} / \mathrm{O}_{3}$ process $\left(\mathrm{mFe}^{0} / \mathrm{O}_{3}\right)$ : Optimization, kinetic, performance and mechanism. Chemical Engineering Journal 302, 137-145 (2016).

8. Jie Lee, W., Bao, Y., Hu, X. \& Lim, T.-T. Hybrid Catalytic Ozonation-Membrane Filtration Process with CeOx and MnOx Impregnated Catalytic Ceramic Membranes for Micropollutants Degradation. Chemical Engineering Journal, https://doi. org/10.1016/j.cej.2019.05.031 (2019).

9. An, T. et al. Kinetics and mechanism of advanced oxidation processes (AOPs) in degradation of ciprofloxacin in water. Applied. Catalysis B: Environmental 94, 288-294, https://doi.org/10.1016/j.apcatb.2009.12.002 (2010).

10. Deng, Y. \& Zhao, R. Advanced Oxidation Processes (AOPs) in Wastewater Treatment. Current Pollution Reports 1, 167-176 (2015).

11. Zhao, L., Ma, J., Sun, Z. \& Liu, H. Mechanism of heterogeneous catalytic ozonation of nitrobenzene in aqueous solution with modified ceramic honeycomb. Applied Catalysis B: Environmental 89, 326-334, https://doi.org/10.1016/j.apcatb.2008.12.009 (2009).

12. Bai, Z., Yang, Q. \& Wang, J. Catalytic ozonation of sulfamethazine antibiotics using $\mathrm{Ce}_{0.1} \mathrm{Fe}_{0.9} \mathrm{OOH}$ : Catalyst preparation and performance. Chemosphere 161, 174-180, https://doi.org/10.1016/j.chemosphere.2016.07.012 (2016).

13. Kurian, M., Kunjachan, C. \& Sreevalsan, A. Catalytic degradation of chlorinated organic pollutants over $\mathrm{Ce}_{\mathrm{x}} \mathrm{Fe}_{1-\mathrm{x}} \mathrm{O}_{2}(\mathrm{x}$ : $0,0.25,0.5$, $0.75,1)$ nanocomposites at mild conditions. Chemical Engineering Journal 308, 67-77, https://doi.org/10.1016/j.cej.2016.09.039 (2017).

14. Zhu, J. et al. Perovskite Oxides: Preparation, Characterizations, and Applications in Heterogeneous Catalysis. ACS Catalysis 4, 2917-2940, https://doi.org/10.1021/cs500606g (2014).

15. Wang, B., Cao, Q. \& Zhang, S. Effects of the incorporation of Fe on the electromagnetic and microwave absorption performance of $\mathrm{La}_{0.7} \mathrm{Sr}_{0.3} \mathrm{MnO}_{3 \pm \delta}$. Materials Science in Semiconductor Processing 19, 101-106, https://doi.org/10.1016/j.mssp.2013.12.010 (2014).

16. Suárez-Vázquez, S. I., Gil, S., García-Vargas, J. M., Cruz-López, A. \& Giroir-Fendler, A. Catalytic oxidation of toluene by SrTi ${ }_{1-}$ ${ }_{\mathrm{X}} \mathrm{B}_{\mathrm{X}} \mathrm{O}_{3}(\mathrm{~B}=\mathrm{Cu}$ and $\mathrm{Mn})$ with dendritic morphology synthesized by one pot hydrothermal route. Applied Catalysis B: Environmental 223, 201-208, https://doi.org/10.1016/j.apcatb.2017.04.042 (2018).

17. Sun, Q. et al. Influence of the surface hydroxyl groups of MnOx/SBA-15 on heterogeneous catalytic ozonation of oxalic acid. Chemical Engineering Journal 242, 348-356, https://doi.org/10.1016/j.cej.2013.12.097 (2014).

18. Liu, H. et al. Structure refinement and luminescence properties of a novel apatite-type compound $\mathrm{Mn}_{2} \mathrm{Gd}_{8}\left(\mathrm{SiO}_{4}\right)_{6} \mathrm{O}_{2} . \mathrm{Dyes}$ and Pigments 140, 87-91, https://doi.org/10.1016/j.dyepig.2017.01.033 (2017).

19. Chen, J. et al. Magnetically Separable and Durable $\mathrm{MnFe}_{2} \mathrm{O}_{4}$ for Efficient Catalytic Ozonation of Organic Pollutants. Industrial \& Engineering Chemistry Research 53, 6297-6306, https://doi.org/10.1021/ie403914r (2014).

20. Martins, R. C. \& Quinta-Ferreira, R. M. Catalytic ozonation of phenolic acids over a Mn-Ce-O catalyst. Applied Catalysis B: Environmental 90, 268-277, https://doi.org/10.1016/j.apcatb.2009.03.023 (2009).

21. Hammouda, S. B. et al. Reactivity of novel Ceria-Perovskite composites $\mathrm{CeO}_{2}-\mathrm{LaMO}_{3}(\mathrm{MCu}, \mathrm{Fe})$ in the catalytic wet peroxidative oxidation of the new emergent pollutant 'Bisphenol F': Characterization, kinetic and mechanism studies. Applied Catalysis B: Environmental 218, 119-136, https://doi.org/10.1016/j.apcatb.2017.06.047 (2017).

22. Zhang, L., Tu, J., Lyu, L. \& Hu, C. Enhanced catalytic degradation of ciprofloxacin over Ce-doped OMS-2 microspheres. Applied Catalysis B: Environmental 181, 561-569, https://doi.org/10.1016/j.apcatb.2015.08.029 (2016).

23. Zhang, J. L. et al. Catalytic ozonation of penicillin G using cerium-loaded natural zeolite (CZ): Efficacy, mechanisms, pathways and toxicity assessment. Chemical Engineering Journal 123144, 1385-8947, https://doi.org/10.1016/j.cej.2019.123144 (2019).

24. Min, J. W. et al. Simple, robust metal fluoride coating on layered $\mathrm{Li}_{1.23} \mathrm{Ni}_{0.13} \mathrm{Co}_{0.14} \mathrm{Mn}_{0.56} \mathrm{O}_{2}$ and its effects on enhanced electrochemical properties. Electrochimica Acta 100, 10-17, https://doi.org/10.1016/j.electacta.2013.03.085 (2013).

25. Wang, X. et al. Mechanism and process of methylene blue degradation by manganese oxides under microwave irradiation. Applied Catalysis B: Environmental 160-161,211-216, https://doi.org/10.1016/j.apcatb.2014.05.009 (2014).

26. Wang, X. et al. Oxygen-assisted preparation of mechanoluminescent ZnS:Mn for dynamic pressure mapping. Nano. Research 11, 1967-1976, https://doi.org/10.1007/s12274-017-1813-y (2018).

27. Liu, W.-T., Tsai, S.-C., Tsai, T.-L., Lee, C.-P. \& Lee, C.-H. Characteristic study for the uranium and cesium sorption on bentonite by using XPS and XANES. Journal of Radioanalytical and Nuclear Chemistry 314, 2237-2241, https://doi.org/10.1007/s10967-0175584-4 (2017).

28. Chang, L. H., Sasirekha, N., Chen, Y. W. \& Wang, W. J. Preferential Oxidation of CO in $\mathrm{H}_{2}$ Stream over Au/MnO $2-C e O=$ Catalysts. Industrial \& Engineering Chemistry Research 45, 4927-4935 (2006).

29. Zou, Z. Q., Meng, M. \& Zha, Y. Q. Surfactant-Assisted Synthesis, Characterizations, and Catalytic Oxidation Mechanisms of the Mesoporous $\mathrm{MnOx}-\mathrm{CeO}_{2}$ and $\mathrm{Pd} / \mathrm{MnOx}-\mathrm{CeO}_{2}$ Catalysts Used for $\mathrm{CO}$ and $\mathrm{C}_{3} \mathrm{H}_{8}$ Oxidation. J.phys.chem.c 114, 468-477 (2014).

30. Lim, J., Yang, Y. \& Hoffmann, M. R. Activation of Peroxymonosulfate by Oxygen Vacancies-Enriched Cobalt-Doped Black TiO Nanotubes for the Removal of Organic Pollutants. Environmental science \& technology 53, 6972-6980, https://doi.org/10.1021/acs. est.9b01449 (2019).

31. Yang, Y. et al. Cobalt-Doped Black $\mathrm{TiO}_{2}$ Nanotube Array as a Stable Anode for Oxygen Evolution and Electrochemical Wastewater Treatment. ACS Catal 8, 4278-4287, https://doi.org/10.1021/acscatal.7b04340 (2018).

32. Gonçalves, A. G., Figueiredo, J. L., Órfão, J. J. M. \& Pereira, M. F. R. Influence of the surface chemistry of multi-walled carbon nanotubes on their activity as ozonation catalysts. Carbon 48, 4369-4381, https://doi.org/10.1016/j.carbon.2010.07.051 (2010).

33. Afzal, S., Quan, X. \& Lu, S. Catalytic performance and an insight into the mechanism of $\mathrm{CeO}_{2}$ nanocrystals with different exposed facets in catalytic ozonation of p-nitrophenol. Applied Catalysis B: Environmental 248, 526-537, https://doi.org/10.1016/j. apcatb.2019.02.010 (2019).

34. Xiong, Z., Lai, B. \& Yang, P. Insight into a highly efficient electrolysis-ozone process for N,N-dimethylacetamide degradation: Quantitative analysis of the role of catalytic ozonation, fenton-like and peroxone reactions. Water research 140, 12-23, https://doi. org/10.1016/j.watres.2018.04.030 (2018).

35. Jia, J., Zhang, P. \& Chen, L. The effect of morphology of $\alpha-\mathrm{MnO}_{2}$ on catalytic decomposition of gaseous ozone. Catalysis Science \&. Technology 6, 5841-5847, https://doi.org/10.1039/c6cy00301j (2016).

36. Cao, J. et al. Degradation of tetracycline by peroxymonosulfate activated with zero-valent iron: Performance, intermediates, toxicity and mechanism. Chemical Engineering Journal 364, 45-56, https://doi.org/10.1016/j.cej.2019.01.113 (2019). 
37. Su, C. et al. Mixed Conducting Perovskite Materials as Superior Catalysts for Fast Aqueous-Phase Advanced Oxidation: A Mechanistic Study. ACS Catalysis 7, 388-397, https://doi.org/10.1021/acscatal.6b02303 (2016).

38. Hao, R., Xiao, X., Zuo, X., Nan, J. \& Zhang, W. Efficient adsorption and visible-light photocatalytic degradation of tetracycline hydrochloride using mesoporous BiOI microspheres. Journal of hazardous materials 209-210, 137-145, https://doi.org/10.1016/j. jhazmat.2012.01.006 (2012).

39. Hou, L., Wang, L., Royer, S. \& Zhang, H. Ultrasound-assisted heterogeneous Fenton-like degradation of tetracycline over a magnetite catalyst. Journal of hazardous materials 302, 458-467, https://doi.org/10.1016/j.jhazmat.2015.09.033 (2016).

40. Zhu, X.-D., Wang, Y.-J., Sun, R.-J. \& Zhou, D.-M. Photocatalytic degradation of tetracycline in aqueous solution by nanosized $\mathrm{TiO}_{2}$. Chemosphere 92, 925-932, https://doi.org/10.1016/j.chemosphere.2013.02.066 (2013).

41. Lv, G. et al. Synthesis of birnessite with adjustable electron spin magnetic moments for the degradation of tetracycline under microwave induction. Chemical Engineering Journal 326, 329-338, https://doi.org/10.1016/j.cej.2017.05.123 (2017).

\section{Acknowledgements}

This present work was supported by the National Key R\&D Program of China (Grant no. 2017YFE0133100), the National Natural Science Foundations of China (Grant Nos 41831288 and 51672257), the Fundamental Research Funds for the Central Universities (Grant Nos 2652018305 and 2652017335). D.V.D is grateful for Russian Science Foundation (Grant 19-77-10013).

\section{Author contributions}

J.F., N.L. and L.M. conceived the project. N.L designed and performed the experiments. J.F., D.D.,Y.B. and J.W. analyzed the data. L.M., L.L., D.D. and G.L. wrote the manuscript. All the authors discussed the results and commented on the manuscript at all stages.

\section{Competing interests}

The authors declare no competing interests.

\section{Additional information}

Correspondence and requests for materials should be addressed to L.M., L.L. or G.L.

Reprints and permissions information is available at www.nature.com/reprints.

Publisher's note Springer Nature remains neutral with regard to jurisdictional claims in published maps and institutional affiliations.

(c) (i) Open Access This article is licensed under a Creative Commons Attribution 4.0 International

License, which permits use, sharing, adaptation, distribution and reproduction in any medium or format, as long as you give appropriate credit to the original author(s) and the source, provide a link to the Creative Commons license, and indicate if changes were made. The images or other third party material in this article are included in the article's Creative Commons license, unless indicated otherwise in a credit line to the material. If material is not included in the article's Creative Commons license and your intended use is not permitted by statutory regulation or exceeds the permitted use, you will need to obtain permission directly from the copyright holder. To view a copy of this license, visit http://creativecommons.org/licenses/by/4.0/.

(c) The Author(s) 2019 